\title{
Mumbai Port and City: Planning for Symbiosis
}

\author{
Hemalata Dandekar \\ PhD.; professor and head of \\ Cal Poly's CRP Department.
}

\author{
Sulakshana Mahajan \\ Urban planner, Mumbai \\ Transportation Support Unit.
}

\begin{abstract}
Globalization, private sector and community pressures, and the need for capturing new revenues are the major factors directing port cities around the world towards redeveloping their old ports and waterfronts. Dandekar and Mahajan discuss the opportunities and challenges faced by Mumbai, one of India's major port cities, in planning for such changes and responding to the need of all stakeholders.
\end{abstract}

$M^{\text {untom }}$ umbai Port has declined in the face of competition from a new port located directly across the water within Mumbai Harbor. Its 1,100 acres of prime waterfront land, now under-utilized, edge Mumbai City's eastern shore. Slum encroachment and illegal underworld activities permeate under-utilized port lands that are coveted by Mumbai, a city that is starved for suitable development sites. However, port lands are controlled by the Mumbai Port Trust (MbPT), not by the city.

Both Mumbai City and Mumbai Port are losing their regional and national dominance. A new city-port synergy, as has been attained in other major port cities of the world, is needed. Pragmatic intra-government negotiations and planning processes which include private and third sector stakeholders are called for if Mumbai's port and city are to reach a new and productive equilibrium. Creative planning intent and processes to achieve it are needed.

\section{Mumbai}

The evolution of Mumbai (formerly Bombay) City is intricately intertwined with its location on the western coast of India and its significant geographical asset-a sheltered port. As with other British colonial port cities, Mumbai's growth and development during British colonial expansion period were intrinsically related to its ties with trade, commerce, and economy, as well as its administrative connections with London. The dendritic transportation and communication infrastructure that the British financed and built emanated from Mumbai City into the productive agricultural, labor-rich hinterland of the Deccan Plateau. The regional connections enabled economic growth not just from trade, but also by helping to fuel industrial production in the core of the colonial city. The growth and viability of Mumbai today continue to be linked with trade and finance, but are no longer dependent on the old port. Transportation infrastructure-primarily rail, road, and more recently a highway network-has been a key factor that facilitated strong regional and national connections. Mumbai City aspires to become a significant global city and to continue to play a leading role in the economy and development of India. But congestion, a declining quality of life, and lack of amenities are causing it to lose ground. Access to port lands is perceived to be a key opportunity for remediation.

\section{Colonial Mumbai}

Seven islands constitute present-day Mumbai. The potential of these islands to serve as a center of trade and commerce that could compete with other ports was recognized by the British. Incentives they offered to skilled workers attracted a diverse and multicultural work force to the city. These workers form the basis of the skilled business community and the multicultural society of today's Mumbai. The British invested in extensive public works, and over some sixty years the seven islands of Bombay were merged into a single land mass. The construction of the Mumbai docks was part of this substantial investment in major infrastructure. The city had the leading port, railway headquarters, textile industries, and the financial sector of the country. Population growth of Mumbai was supported by the growth and diversification of the economy, making the city the land of opportunity. Mumbai's population growth accelerated following independence and the partition of the country into India and Pakistan. Between 1941 and 1951 the city grew at a rate of more than $5 \%$, due to an influx of refugees from Pakistan and in-migration from other parts of India for jobs. In 1951, with a population of 4.6 million, Mumbai was the second largest city in independent India (after Calcutta).

\section{Post-Independence}

During colonial rule all public authorities operated under a common and singular goal of maximizing economic benefits. After independence in 1947, development strategies of the port, railways, textile mills, and finance and banking sectors 
started to develop in different directions as they sought an economic competitive edge in new, emerging sectors of the economy. Post-independence economic benefits were seen as secondary to non-economic public interests such as attaining social equity. In addition, diverse agendas were operative at different levels of government-central, state, and local or municipal. Even though all the public sector authorities operating in Mumbai are mandated to serve the "larger Public interests", the understanding of public interests varies greatly as defined by national, state, or local governments. Agencies are insulated from each other and they vary in their understanding of, and accountability to, local priorities. Various governmental agencies also control the diverse sectors that must coordinate and collaborate to bring about changes in key port activity. Mumbai Port Trust (MbPT) is housed under the central government's Ministry of Shipping, and there is no single coordinating authority with power to act across sectors to bring about synergy between the city and the port.

\section{Post-Independence City Growth}

Between 1951 and 1981 the greater Bombay region grew an average of $3.5 \%$ annually, mostly in the northern suburban areas of the city where the growth rate was almost $8 \%$. The long, narrow land mass of the peninsula made for increasing congestion, traffic jams, and long commute times from dormitory suburbs to downtown jobs. By 1991 two-thirds of the Greater Bombay population lived off the island in the suburbs. Most new industrial development was directed away from Bombay across the harbor, where a new twin city - Navi (new) Mumbai-was planned to help decongest the city.

\section{Mumbai Port Expansion}

The expansion of Mumbai's port continued after Indian independence in 1947 well into the 1970s. In Mumbai
Port, Jawahar Dweep was created to handle crude and petroleum while the Pirpau Jetty was constructed to handle liquid chemicals and petroleum products. Four oil berths capable of handling large tankers, a modern jetty, and a number of new upgraded pipelines were added from Pirpau to Jawahar Dweep between 1988 and 1996. Most of the expansion was designed to handle imported petroleum and chemical products that were used by petrochemical industries on the shores of Mumbai as well as Navi Mumbai. Mumbai Port had a total of 63 anchorage points and was the largest port in India, handling the highest amount of cargo. It provided employment to some 40,000 workers directly and many more indirectly.

A new institutional framework for major ports in India was established by the Central Government Act of 1966 that stipulated that each port would be administered by a Board of Trustees (a majority of whom were appointed by the Government of India) and operated under policy directives from the Central Government. Port Trusts were expected to serve the public interest-not to maximize profits or revenues or optimize the deployment of their assets such as land. Port activities also needed to conform to the Dock Workers (Regulation and Employment) Act of 1948 that protected the interests of dock workers; it established rules of service, standards of work and welfare, and, more significantly, assured dock workers complete job security. Port Trusts were also affected by the Merchant Shipping Act of 1958 and the Environment Protection Act of 1968, that had the effect of restricting the expansion and modernization of old ports like Mumbai. But the acts also enabled the creation of new ports by the public sector. Nhava Sheva Port established across the bay was declared a "Major Port" and its name was changed to Jawaharlal Nehru Port (JNPT) when it started its operations in 1989. The new port enjoyed significant transportation and locational advantages and lower land costs.
Figure 1: View of the southern tip of Mumbai, showing part of the port (left) and the Colaba and Cuffe Parade residential districts. (from http://www.enjoyindiantrip.com; access 10/30/13)

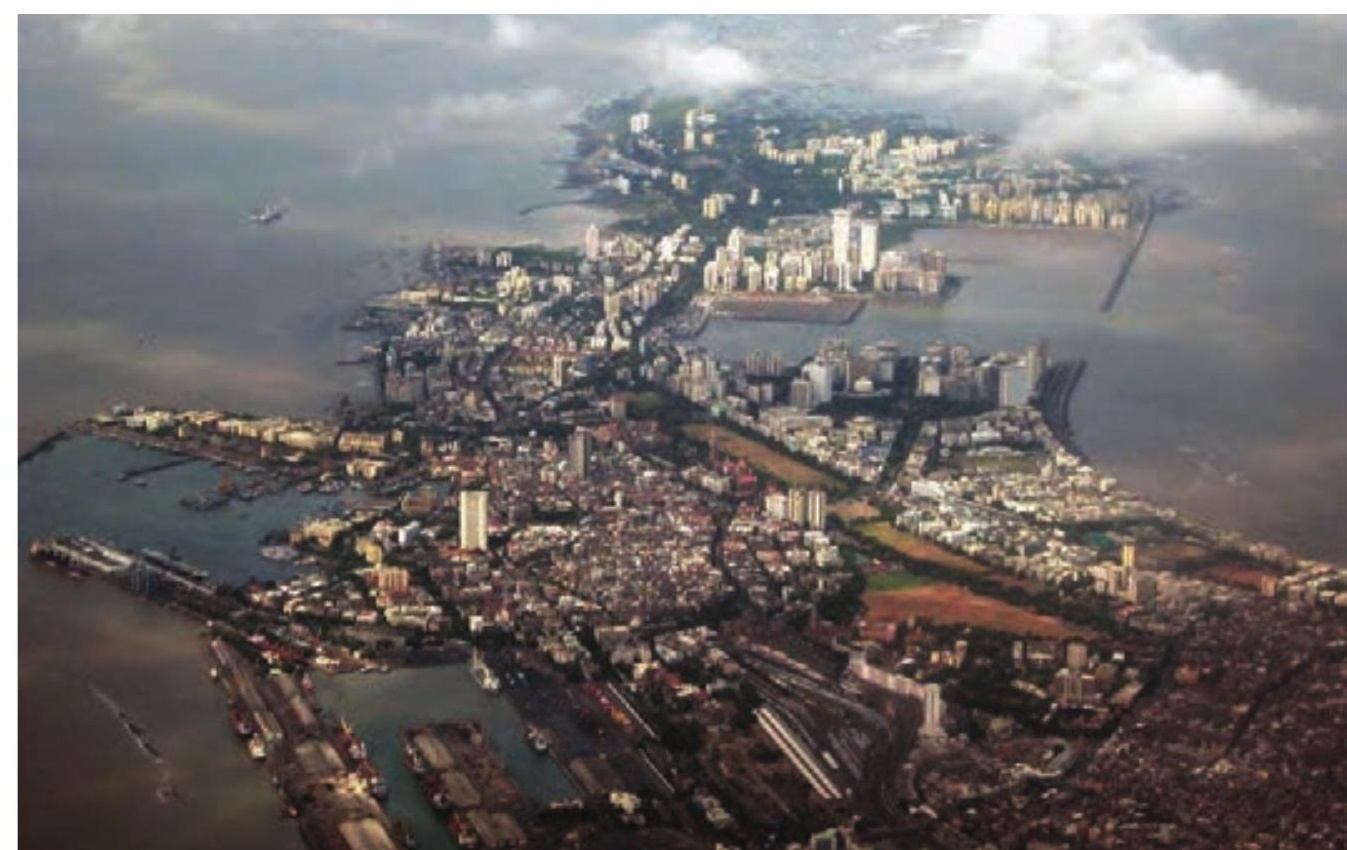




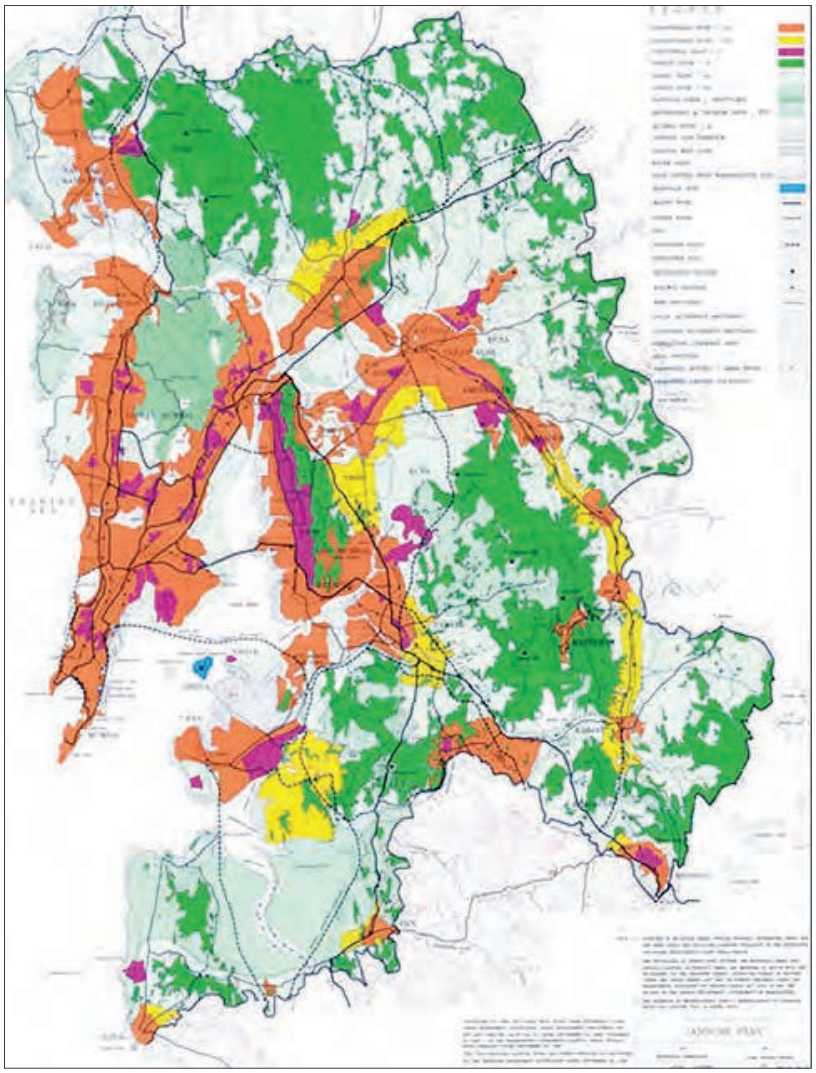

Figure 2: Concept Plan for the Mumbai Metropolitan Region. (from http://www.visionmumbai.com; access 10/30/13)

\section{New Industries}

The first integrated petrochemical industry, which also included fertilizers and pesticides, started functioning at Trombay, Navi Mumbai in 1966. It depended on imported petroleum products handled by Mumbai Port. Large engineering, pharmaceutical, printing, auto, as well ancillary medium and small industries expanded from 1960 to 1990 in Mumbai suburban areas to the north and along the eastern and western railway corridors. These industries attracted migrants to the Mumbai region and resulted in the growth of regional cities. The government and public sector industries, such as telecommunications, metal, and engineering, also added to the employment in suburban areas of Mumbai. Following nationalization of many private banks in the late 1960s, banking and finance operations also expanded substantially in Mumbai while heavy industries declined. Thus in the decades after independence, the foundation of a service economy was established in Mumbai.

\section{Post-Liberalization Globalization}

The new policy of globalization, privatization, and liberalization charted by the Central Government in the 1990s created major challenges for Mumbai City and
Mumbai Port. The traditional industries that had flourished within the city declined, and financial and other services grew both within the city and in the region. A private sector group, Bombay (Mumbai) First, advocated for publicprivate partnerships in creating a Bombay that would be a competitive player in the global economy and reinvent its base economy through a variety of transformations of industry and product.

Their 2010 Concept Plan for Mumbai Metropolitan Region (Figure 2) visualizes ambitious plans for the development of the physical infrastructure of the city-region, including large-scale land reclamation and creation of new islands in Mumbai Harbor. It envisions a shift in the city economy to tertiary services (from $71 \%$ in 2008 to $76 \%$ by 2052 ) with a high emphasis on skilled human capital, and a high rate of growth in business services and $24 \%$ employment in the secondary sector. ${ }^{1}$ These projections and the State Government's initiatives to grow IT services had the effect of drawing attention away from the old economy of manufacturing, chemicals, and trade for which the port was key infrastructure. The growth of the new service economy largely rested on the city's ability to provide high-end financial and IT services and cater to other high-skilled service sectors such as diamond cutting and trade, and on facilitating construction of infrastructure. In this new economy, the need to develop a symbiotic relationship between the port and the city has now emerged with greater urgency.

\section{Mumbai and Navi Mumbai Port Relationship}

As trade was expanding under neo-liberalization policies so was the need for port infrastructure. The new port policy undermined the identity of Mumbai as a port city connected to its manufacturing hinterland. Infrastructure in the Mumbai dockyards was underused and some of the port activities started to decline even though the petroleum product handling increased. The Port Trust's workforce declined by $50 \%$ from 1990 to 2005 , with the introduction of the Voluntary Retirement Scheme (VRS). With this decline in numbers the political strength of the dockworkers' union also declined. From 2003 to 2006 investments in fixed assets and capital expenditure by Mumbai Port declined while expenditure went up substantially due to contributions

\footnotetext{
${ }^{1}$ See pg. 6 of the 2010 Concept Plan power point at http:// www.mumbaifirst.org. Bombay First "drew inspiration from the emergence of London First, which assumed the role of facilitating the restructuring of London through various Public Private Partnership initiatives. As the big business houses in London came together to form London First, the major industries and business houses in Mumbai came together to create Bombay First. Bombay First has been formed largely as a think tank of the city, and also to assume a more specific role of fostering partnerships between various major stakeholders. Big business houses and financial institutions have made contributions to create a corpus for the functioning of Bombay First. It uses the means of researching, catalyzing, advocating, and networking to fulfill this role mission. Bombay First today has become one of the most successful examples of Public Private Partnership."
} 
that had to be made to the Pension Fund Trust. Though operating profit had increased, net profit after tax became zero in 2005-06. ${ }^{2}$

This decline of Mumbai Port was in sharp contrast to the growth of other major ports on the western coast of India, including JNPT. The growth of JNPT across the harbor in Navi Mumbai has been especially significant as the port was able to increase its capacity to handle liquid products with innovative policies. After the reforms, JNPT, which was mainly entrusted to handle container traffic, was able to expand and diversify its operations with innovative methods. As Ray (2004: 18) notes, "JNPT contracted with two major public sector oil companies, Bharat Petroleum Corporation Ltd. (BPCL) and Indian Oil Corporation Ltd. (IOCL) to develop a new dedicated state-of-the-art liquid cargo handling facility ... with the objective of shifting the entire handling of POL (petroleum-oil-lubricant) products and other liquid cargo to this terminal."

JNPT was also equipped with a modern IT-based communication system, vessel management system, and electronic data interchange facilities, which allowed for efficient communication between the port and port users and customs. It was also well connected to its hinterland and the rest of India by national highways and the Konkan Railway. An important dedicated high-speed rail projectDelhi Mumbai Freight Corridor (DMFC) - is now underway; this would link JNPT with North India. These new developments are likely to further undermine Mumbai Port in the future, making it difficult to revitalize its traditional activities.

\section{Repurposing Mumbai Port Lands}

In Mumbai land for housing, service provision, and commerce is in acutely short supply. The under-utilization of the Mumbai Port lands is documented and mapped in great detail in Mehrotra et. al.'s A Study on the Eastern Waterfront of Mumbai (see particularly page 12-suboptimal port use-and page 25-potentials of real estate). This spatial mapping and analysis of the eastern waterfront highlights the fact that the MbPT land, infrastructure, and waterfront offers an opportunity to "mend" or enhance the urban fabric of downtown Mumbai, and improve the amenities and quality of life in Mumbai City.

Mumbai's eastern waterfront is a tremendous asset, which can become a key element in creating the type of environment that is attractive to the financial, banking, corporate, and entertainment sectors that are the engines of Mumbai's economy today. The eastern waterfront has been effectively locked away and made inaccessible to most civilian activities for the last century. It has been an area

\footnotetext{
${ }^{2}$ Mumbai Port Business Plan, final report, volume I.
}

basically "walled off" from the daily life and hustle and bustle of Mumbai city life and its commercial economy. Commuters on the Harbor Railway which edges the docklands obtained only tantalizing glimpses of the dilapidated, discarded buildings, warehouses, and infrastructure that occupy the port area. To the working Mumbaite commuting to work downtown, the eastern dock area had been a mysterious no-entry land. However, although the pressure to turn over port land has been successfully resisted so far by the MbPT, it has had to concede to a demand for land for infrastructure. Thus a new, 10-mile-long Eastern Freeway, running above the existing main port road parallel to the Harbor Railway, has recently been completed. The elevated road provides much clearer views of the dichotomy between the dense city fabric of Mumbai City to the west and the underutilized Mumbai Port lands to the east. Mumbai City has been pressing MbPT to open up the eastern waterfront for the benefit of the city.

The port lands represent an asset that is highly contested, due to its geography, history, and strategic location edging a congested and dense island city. Suggestions for its use range from amenity-based, high-end leisure activity to those offered by the Mumbai Port Trust for increasing port activity at strategic sites along the eastern waterfront. Numerous constituencies have a stake in the outcomes of these land development decisions. Industrial facilities, the dock infrastructure, related storage and processing areas and buildings, the illegal squatter settlements, and underworld activities have infiltrated these areas and occupy the land resource.

In 2002 eleven government, seventeen private, five NGOs, and ten labor groups were stakeholders in this area (Mehrotra et al., 2005: 8). These stakeholders hold contradictory positions on how the scarce resource of Mumbai's eastern waterfront docklands, industrial infrastructure, buildings, and utilities need to be repurposed to optimize their economic, social, or civic usefulness in the global economy of the 21 st century. They range from refurbishing the old port infrastructure and striving to return the area to its primary purpose as an entry port for goods and people (as suggested by proposals from the MbPT) to NGO claims on lands, some already occupied by squatter settlements, to create social housing needed by the poor.

All have legitimacy and rationality that is consistent within their internal frameworks. But lost in this contestation is the issue of what is needed in the new global economy to jump-start and support the heart of a city that is in economic transition. The east dockland waterfront successfully serviced the city and maintained its competitive edge during the industrial period. It is poised to be able to play a similar role in the new knowledge and service economy of the 21 st century - if processes can be aligned to enable this role. 


\section{Repurposing Mumbai Port for Synergy with the City}

The potential of the eastern waterfront to play a key role in integrating Mumbai Region with growth nodes of economic activity, people, manufacturing, and transportation infrastructure is clearly illustrated in many concept designs for the region. The successes of San Francisco and Silicon Valley in the South Bay Area, Lisbon's modern transit center and revamping of port land into new urban facilities and amenities, Rotterdam's expansion of new container port infrastructure onto reclaimed land into the sea, Baltimore's amenity-laden, recreational tourism- based revitalization, and New York's resilience in repurposing port areas are immediately evoked. London's dock area, particularly the now well-known case of the Canary Docks area and India Docks - the main receiving point of bulk goods from Mumbai during colonial times- now transformed to office, commercial, service, and housing usage, is referenced.

Reviewing the current literature on what these cities have achieved and are proposing with repurposed port land is instructive. It reveals what may be possible. Although case study comparisons are enlightening, they have limited direct utility. These successes are based on the technical, spatial, geographic parameters, resource base, and overall configuration of the particular landscape and what it logically allows. Most case studies do not explicate the fact that making changes in key infrastructure is a politicized, power-based activity in which technical rationality plays a role, but does not usually determine decisions. Longstanding interests, timing, and political clout are important signifiers, varying greatly depending on the point in history and the specific context.

Peterson and Thawakar (2013: 15) describe the value of government-owned land in the Mumbai Port area, underscoring the possibilities inherent in converting the value of just some of this land to provide the finance capital needed for infrastructure and other investments to bring about redevelopment in the city and the port areas. They argue:

"200 hectares can be managed, over the long run, according to economic and urban development principles. Given recent land pricing in Mumbai, this patrimony would have a value of roughly 125,000 crore Rupees, or in the range of US $\$ 25$ billion. The financial value of Port land need not dictate decisions about land use. It does justify managing Port land as a coherent estate, where genuinely surplus land is identified, and land values can be converted from time to time into critical infrastructure investments."

They go on to note that the key landholder, the MbPT, does not support transformation of land use from port-related uses to other kinds of occupancy.

An important component of reinventing traditional port city cores around the world has involved the preservation and adaptive reuse of the historic, cultural, and architectural fabric, and developing the historic narrative of the old city and port. Attention to this patrimony has enabled successful economic redevelopment strategies centered on tourism, such as in the pioneer cases of Boston and Baltimore. Preservation of the historic city core to stimulate tourism as an economic catalyst has been part of the underpinning of many successfully revitalized city cores that are proximate to a historic port and docks. The fact that revitalized downtowns and adaptively reused historic buildings provide a cachet and legitimacy to multinational industries that appropriate these sites for their facilities has been noted in a variety of contexts. The process is evident in the Ballard Estate area of Mumbai adjoining the entryway to MbPT lands (Mehrotra, 1998).

Peterson and Thawakar's discussion of land values of property under ownership of the government underscores the fact that capital needed to finance investments in critical infrastructure and to create the environment and synergy that would allow private investment capital to flow into the city and improve the physical fabric is at handor underfoot-for cash- starved government entities in Mumbai. The complexity and challenge lies in creating the vision and the approach that will work in a society that is a functioning democracy, one in which economic revival which results in gentrification, takings, and removal and relocation is constrained and tempered by laws that protect slum residents' right to land tenure and access to shelter. It is a society in which there are stakeholders that demand a development that meets the needs of the working class and the middle class, and, the government must, at some level, listen.

\section{Generating Alternative Redevelopment Futures}

To attain an outcome that is considered a win-win by a majority of the many stakeholders, the MbPT docklands need to be utilized and repurposed so that the service they enable can capitalize on the resources of Mumbai City and help revitalize its physical, cultural, and social fabric. The options delineated by various architect and planning groups over the last decade or two have visualized many strategies in a compelling way. Examples include:

a) Mumbai First suggestions present a rich visualization of cruise-ships-driven, entertainment- and recreationcentered development by repurposing the dock area near Cotton Green railway station to create an entertainment and recreation zone that would benefit residents and tourists alike. It outlines bridge and water connections across the bay to network the area into a whole. Such cross-bay connections might serve to make the port a complementary and synergetic, if not integral, part of Mumbai City as well as regionally integrate waterfront and port-related activities around Mumbai's Thane Creek, including the JNPT port. 
b) A concept plan by Singapore-based consultants Surbana addresses a regional solution that involves the development of Mumbai-Navi Mumbai to take advantage of the safety of the Mumbai Harbor. It involves systematically building activities around the harbor (Figures 3 to 4 ) and links them with transport connections consisting of highways and metro and suburban trains. The comprehensive transportation plan has a goal that commuting from "anywhere to anywhere in MMR is not to be more than one hour"- a radical and transformative ideal for a city beleaguered by extremely long and exhausting commuting patterns. The long-term plan envisions the creation of more waterfront with islands of reclaimed land in the middle of the harbor providing recreational beaches, green parks on the waterfront, and sites for entertainment and tourism. These are interlinked with regional sea transport launched from the historic refurbished dock named Bhaucha Dhakka. The plan calls for shifting the functions of Mumbai Port and the existing international and domestic airport at Santa Cruz in Mumbai's western suburbs to the city of Alibaug. It envisions connections to this airport through a rapid transit coastal train and a new highway to navigate the approximately 31-mile distance.

New service economies are evolving to be the leading sectors of Mumbai's post-liberalization economy. So far, plans for the MbPT docklands have offered little concrete suggestions for ways to help provide necessary housing, services, support industries, and amenity environments for the skilled and knowledge workers they need. The Surbana plan proposes high-end housing, hotels, restaurants, and parks in waterfront-facing land, and middle-end and affordable housing behind on the MbPT land and also on reclaimed islands. Support industries would be located in suburban as well as the new Mumbai area rather than in the heart of the city.

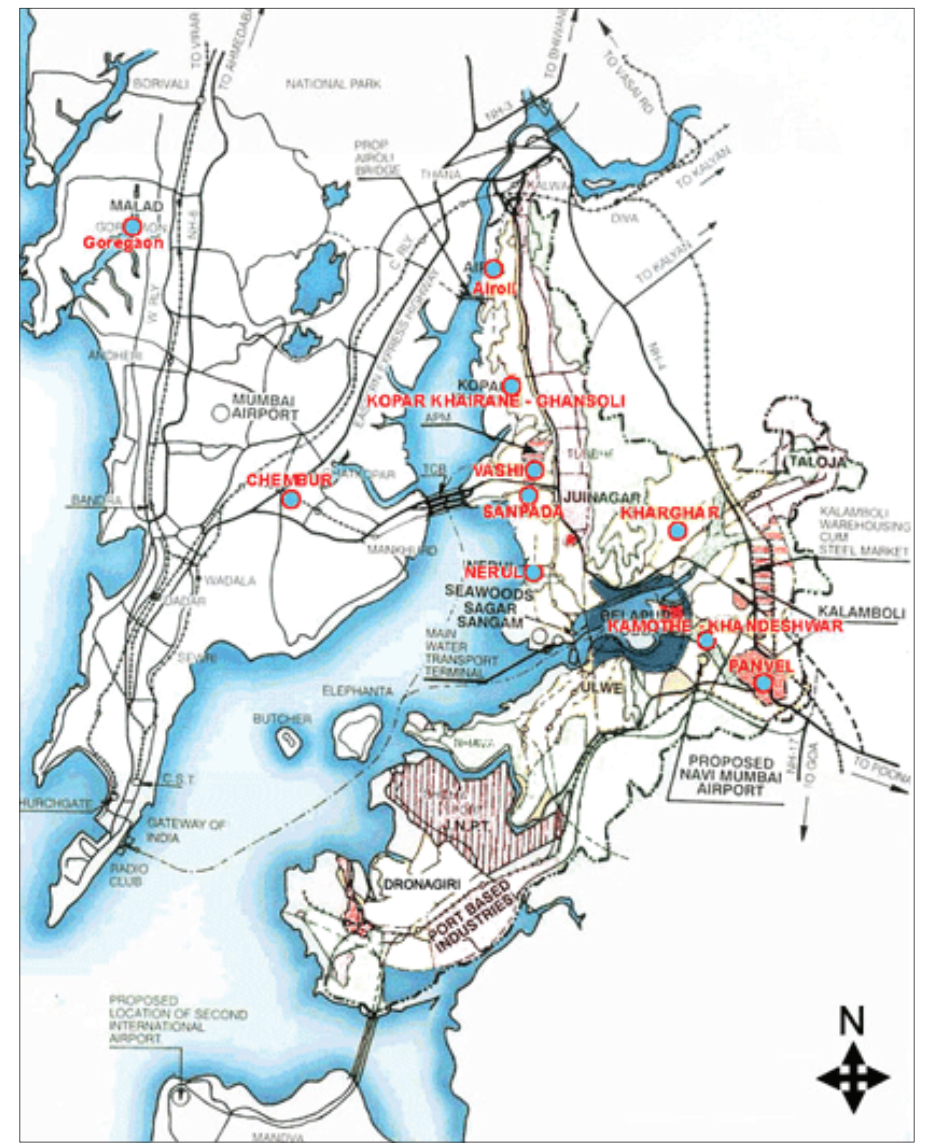

Figure 3: A view of the plan for Mumbai Region and the Navi New Town, by Surbana Consultants. (from http://Www.surbana.com; access 10/30/13)
Figure 4: An analytic sketch showing the proposed new uses taking the areas originally dedicated to the port.

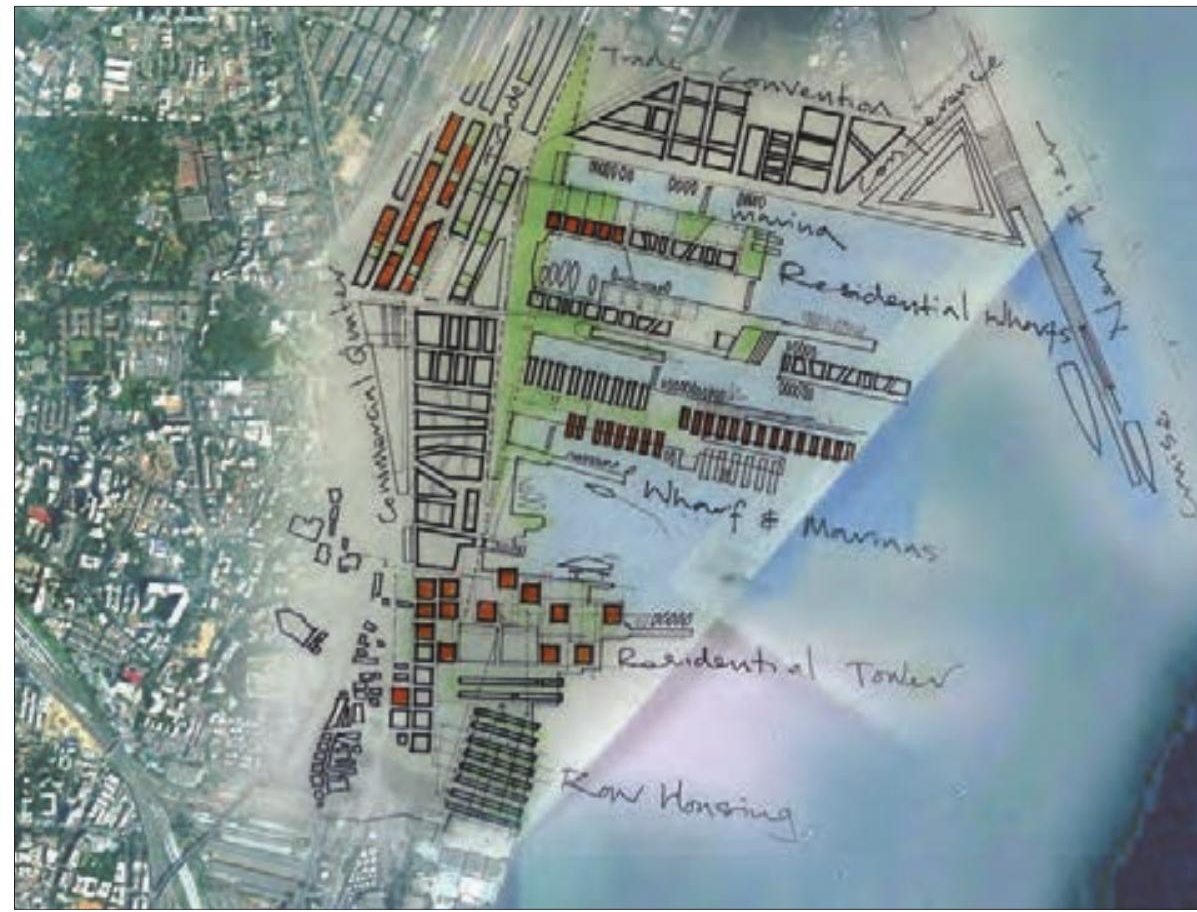



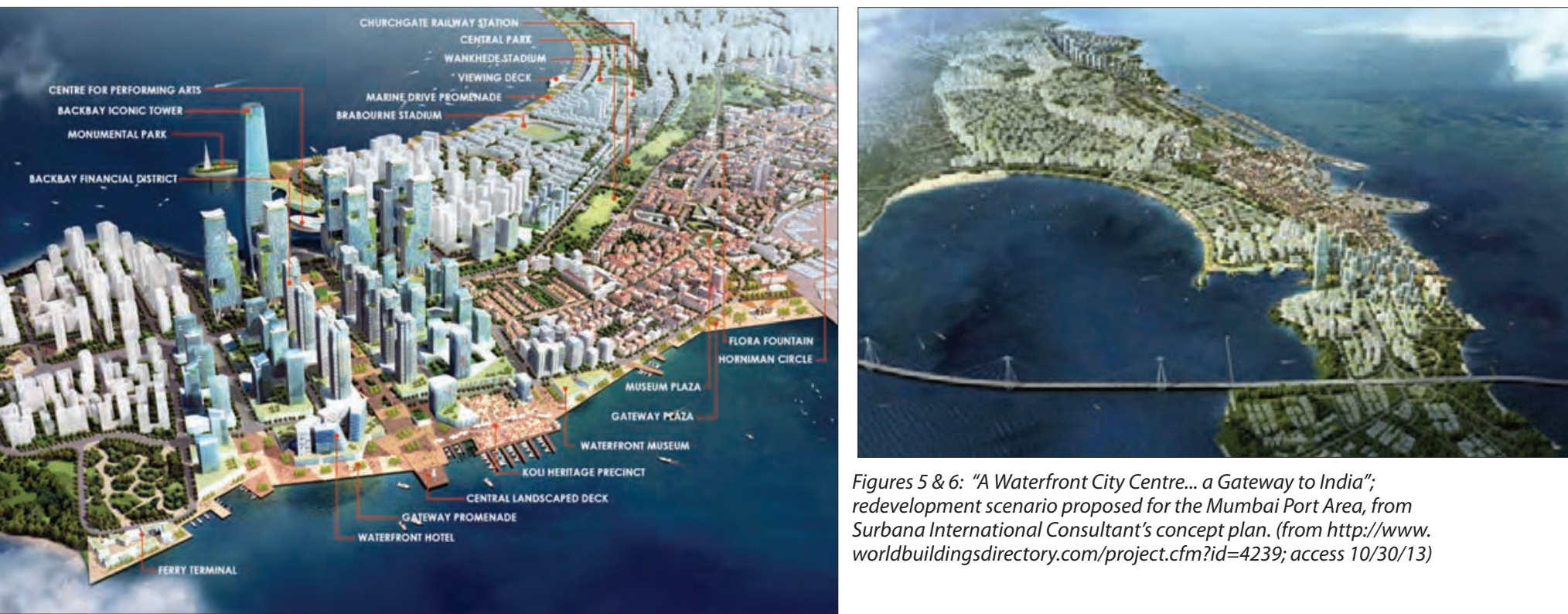

Figures 5 \& 6: "A Waterfront City Centre... a Gateway to India"; redevelopment scenario proposed for the Mumbai Port Area, from Surbana International Consultant's concept plan. (from http://www. worldbuildingsdirectory.com/project.cfm?id=4239; access 10/30/13)

The plan concentrates tourism efforts in the heart of the city in South Mumbai to capitalize on the area's history, shopping, high-end recreation/restaurants, museums, culture, and historical built form. It creates a heritage district that features and highlights the tourist attractions-museum and art galleries, theaters, and shopping - that have long existed in this area of the city. The Surbana plan suggests creating a new Central Business District for finances and a stock exchange in the Colaba area, linked with an underground Metro and highway link (Figure 5). Enhancing passenger traffic and cruise line traffic in the MbPT area continues a long tradition of the Mumbai docks serving the passenger traffic of generations of travelers, particularly those during the colonial period who left India to travel to England. In the 1950s, boats of the P \&O line would leave from Ballard Estate for England and return passengers there. New opportunities for such arrivals and departures would create a contemporary face and opportunity for this historic connection.

Although IT incubator spaces that allow amenity workers opportunities to live on the waterfront and enjoy a quality of life have been used as revitalization catalysts in cities such as Barcelona, the concept plans for Mumbai suggest that there is not much scope for this on Mumbai island. However, media-related IT services are becoming concentrated in Mumbai's western suburbs around film city and Malad. IT is growing in the Navi Mumbai area through the conversion of old, large petrochemical industries into IT parks, data centers, processing units, etc. Some IT companies are relocating on the borders of Thane Creek in Navi Mumbai. Although a few back office functions may continue in the region there has been little innovation, except in and around IIT Powai.
A key issue that needs to be addressed is the role and opportunity for creating social housing in the redevelopment agenda. This is a huge challenge for a city where $65 \%$ of the population is estimated to live in slum settlements. Some slum redevelopment involving construction of 300,000 or so units and rented cessed buildings in Mumbai has occurred, but in a very disorganized manner. ${ }^{3}$ For instance, the Slum Rehabilitation Authority (SRA) and Maharashtra Housing and Area Development Authority (MHADA) have constructed a large number of tenements (around 50,000) for people who had informally occupied land earmarked for infrastructure projects (such as railways, highways etc.) and who are provided with houses at other locations with funds from the project. ${ }^{4}$

In the democratic structure of Indian politics and the multicultural, variegated (differentiated by castes and also class) society and culture of Mumbai City, an approach to redevelopment of the historic docklands and port must involve a strategy in which a majority of the parties recognize that they have a stake and some share of the benefits.

\footnotetext{
${ }^{3}$ Cessed buildings are those maintained by the Mumbai Repair and Reconstruction Board, a public authority, that collects a special cess from the tenants, a tax commonly referred to as the "repair fund". ${ }^{4}$ The task of providing social housing in the city of Mumbai is formidable and daunting. The two agencies charged with addressing this task, Slum Rehabilitation Authority (SRA) (see http://www.sra. gov.in/) and Maharashtra Housing and Area Development Authority (MHADA (see http://mhada.maharashtra.gov.in/?q=home), have been active in creating new opportunities for building units, usually in the lower-land-value areas in the suburbs. The Maharashtra Housing and Area Development Act, 1976 (MHADA) makes special provisions for repairs and reconstruction of "cessed" buildings.
} 
Plans and visions for reconfiguring the region have been presented for at least the last fifty years. ${ }^{5}$ Some of their aspects (the concept of a twin city for instance, that is New Mumbai or Navi Mumbai across the harbor) were actualized, but not as strategically and not in the linear and efficient manner that was envisioned. For instance, rail and road infrastructure links did not get built before the construction of the city, but came up afterward and even today are not yet as planned. Clearly none of the current plans will ever be directly adopted on the basis of their technical rationality and worth. Given the economic impact of planning actions in the public domain, such adoption would be unrealistic. Political pressures on the process and the decision makers will be tremendous. Decisive action is needed; this requires that an extremely strong political will emerges within the leadership in Mumbai (as it has in cities such as Hyderabad and Ahmedabad), leadership which convinces, cajoles, or defies all other authorities with its strong vision and power to force cooperation.

A more realistic outcome for the Mumbai context is probably one that involves compromise and accommodation, as well as a somewhat ad-hoc, neo-liberal set of somewhat piecemeal actions within an overall development concept that is generally acquiesced to. A good planning process that is inclusive is needed. In addition, a vision and its various strategies and objectives must explore and reflect the competitive advantages of being at the historic core of the city.

Suggestions for Mumbai port lands need to fit with the economic direction and movement of the city economy and city needs. They must augment and be in synchrony with the overall economic direction of the metropolitan region. Careful consideration must be given to identifying the kinds of activities and functions that might best be located on the eastern waterfront so as to draw on and strengthen the traditional city center and create a "city heart" which also embraces the port and the eastern dockyard area as a key element of the city past and the city present. Lastly, a planning process is needed that is inclusive of, and able to mediate between, the desires of the diversity of stakeholders who have claims rights on the city.

\footnotetext{
5 See, for instance: Correa, Charles; Pravina Mehta, and Shirish Patel "Planning for Bombay - Patterns of Growth, The Twin City, Current Proposals" (in MARG \# 3, June 1965, pp. 29-56). This was a special issue of MARG on the development of Bombay, highlighting its colonial history and city development and dedicated, according to its editorial, to help solve a problem "on which will depend, literally the life or death of seven million people."The stakes are even higher today, as the Mumbai region now has a population of 17 million.
}

\section{References}

Mehrotra, Rahul. 1998. Bazaars in Victorian Arcades: Conserving Bombay's Historic Core. In Hemalata C. Dandekar (ed.) City Space + Globalization: An International Perspective. Ann Arbor: College of Architecture, University of Michigan.

Mehrotra, Rahul; Pankaj, Joshi and Anirudh, Paul. 2005. A Study on the Eastern Waterfront of Mumbai. Mumbai: Kamla Raheja Vidyanidhi Institute of Architecture / Urban Design Research Institute.

Peterson, George E. and Thawakar, Vasudha. 2013. Capturing the Value of Public Land for Urban Infrastructure: Centrally Controlled Landholdings. Paper presented at the Annual World Bank Conference on Land and Poverty. The World Bank, Washington, DC.

Ray, Amit S. 2004. Managing Port Reforms in India: A Case Study of Jawaharlal Nehru Port Trust (JNPT). Mumbai: Background Paper for the World Development Report 2005, February 15, 2004. Available at http://siteresources.worldbank.org/INTWDR2005/ Resources/477407-1096581040435/wdr2005_india port_reform2.pdf (accessed 3/10/13). 